\title{
Real Time Volcanic Cloud Products and Predictions for Aviation Alerts
}

\author{
Nickolay A. Krotkov, Shahid Habib, and Arlindo da Silva \\ NASA Goddard Space Flight Center, Greenbelt, MD \\ Eric Hughes and Kai Yang \\ University of Maryland, College Park, Department of Atmospheric and Oceanic Sciences, College Park, MD. USA \\ Kelvin Brentzel \\ NASA Goddard Space Flight Center, Direct Readout Laboratory, Greenbelt, MD. USA \\ Colin Seftor and Jason Y. Li \\ NASA Suomi-NPP Ozone PEATE, SSAI, Lanham, MD. USA \\ David Schneider \\ United States Geological Survey, Alaska Volcano Observatory, Anchorage, AK. USA \\ Marianne Guffanti \\ United States Geological Survey Reston, VA. USA \\ Robert L. Hoffman and Tim Myers \\ Metron Aviation Inc. Dulles, VA. USA \\ and \\ Johanna Tamminen and Seppo Hassinen \\ Finnish Meteorological Institute, Helsinki Finland
}

\begin{abstract}
Volcanic eruptions can inject significant amounts of sulfur dioxide $\left.\mathrm{(SO}_{2}\right)$ and volcanic ash into the atmosphere, posing a substantial risk to aviation safety. Ingesting near-real time and Direct Readout satellite volcanic cloud data is vital for improving reliability of volcanic ash forecasts and mitigating the effects of volcanic eruptions on aviation and the economy. NASA volcanic products from the Ozone Monitoring Insrument (OMI) aboard the Aura satellite have been incorporated into Decision Support Systems of many operational agencies. With the Aura mission approaching its 10th anniversary, there is an urgent need to replace OMI data with those from the next generation operational NASA/NOAA Suomi National Polar Partnership (SNPP) satellite. The data provided from these instruments are being incorporated into forecasting models to provide quantitative ash forecasts for air traffic management.

This study demonstrates the feasibility of the volcanic near-real time and Direct Readout data products from the new Ozone Monitoring and Profiling Suite (OMPS) ultraviolet sensor onboard SNPP for monitoring and forecasting volcanic clouds. The transition of NASA data production to our operational partners is outlined. Satellite observations are used to constrain volcanic cloud simulations and improve estimates of eruption parameters, resulting in more accurate forecasts. This is demonstrated for the 2012 eruption of Copahue. Volcanic eruptions are modeled using the Goddard Earth Observing System, Version 5 (GEOS-5) and the Goddard Chemistry Aerosol and Radiation Transport (GOCART) model. A hindcast of the disruptive eruption from Iceland's Eyjafjallajokull is used to estimate aviation re-routing costs using Metron Aviation's ATM Tools.
\end{abstract}

1

American Institute of Aeronautics and Astronautics 


\section{Introduction}

$\mathrm{V}$

OLCANIC eruptions can inject significant amounts of sulfur dioxide $\left(\mathrm{SO}_{2}\right)$ and Volcanic Ash (VA) into the atmosphere at commercial aircraft cruising altitudes. This poses a substantial risk to aviation safety since many of these eruptions can occur sporadically and with very little warning. In the past 30 years nearly 80 jet aircraft have sustained damage after flying into volcanic clouds [Guffanti et al. 2010]. In the most dangerous encounters, VA caused in-flight engine failures in large commercial passenger jets. Imprecise knowledge of volcanic cloud position can cause flight cancellations; and diversions and excess fuel burn due to rerouting. In one example, uncertainty in the position of ash clouds from the April 2010 eruptions of Eyjafjallajökull volcano in Iceland caused a shutdown of the entire Northern European airspace for several days resulting in travel disruptions and significant economic losses ( $\$ 1.7$ billion in lost airline revenue [ESA 2010]). To mitigate such disruptions regulators are revising flight policies through airspace affected by VA. New policies and flight rules will require enhanced Decision Support Systems (DSS) incorporating data from advanced satellite sensors.

NASA produces volcanic products of $\mathrm{SO}_{2}$ and $\mathrm{AI}$ (Aerosol Index/Ash) from the Aura/OMI UV sensor and processes them in near-real time (NRT), with a latency of less than 3 hours since time of observation. These volcanic products have been incorporated into the Decision Support Systems (DSS) of many operational agencies, including NOAA (http://satepsanone.nesdis.noaa.gov/pub/OMI/OMISO2/index.html) and the European Support to Aviation Control Service (http://sacs.aeronomie.be/nrt/ ). Direct Readout (DR) of $\mathrm{OMI} \mathrm{SO}_{2}$ and AI data over North Atlantic and Europe by the Finnish Meteorological Institute (FMI) are processed within 15 min after the NASA Aura satellite overpass of the Sodankylä ground station (http://omivfd.fmi.fi/volcanic.html). With the Aura mission approaching its 10th anniversary, there is an urgent need to ensure continuity of the OMI data with those from the next generation operational NASA/NOAA Suomi National Polar Partnership (S-NPP) satellite and incorporating it into quantitative ash forecasts for air traffic management (ATM). The Ozone Monitoring and Profiling Suite (OMPS) UV sensor aboard S-NPP began producing volcanic products in December of 2012. These products are similar to those produced from OMI. Details about the OMPS data products are outlined in Section II.

Satellite observations demonstrate a clear utility for monitoring the location of volcanic clouds, but these products can also be incorporated into volcanic emissions models for better forecasts. By using satellite observations to constrain model simulations, initial eruption parameters can be accurately estimated (see Section IV). In Section V, the resulting forecasts are fed into an advanced Decision Support Systems (DSS) which optimizes the rerouting of air traffic around volcanic clouds.

\section{Volcanic Products from OMPS}

The Ozone Mapping and Profiler Suite (OMPS) instrument was successfully put into orbit onboard the NASA/NOAA/DOD operational Suomi National Polar-orbiting Partnership (SNPP) weather satellite on October 28, 2011. The OMPS instrument began making earth observations in the Fall of 2012 and is expected to have a 7 year lifetime. As it's name suggests, OMPS consists of both a profiling sensor and a nadir mapping sensor. The profiling sensor measures in a vertical profile from the stratosphere upwards to $60 \mathrm{~km}$, while the nadir mapping sensor has a ground swath of $50 \mathrm{~km} \times 2800 \mathrm{~km}$ which provides daily global coverage. Although the altitude of the profiling sensor measurements is too high to be useful for aviation interest, the daily global maps produced from the nadir sensor provide useful information about the horizontal distribution of trace gases in the atmosphere.

The OMPS instrument was designed to derive accurate global ozone data, using measured radiance from reflected sunlight in the UV range from 300 to $380 \mathrm{~nm}$. This new generation instrument is well designed, with a very high measurement signal-to-noise ratio, allowing many other atmospheric constituents to be retrieved including $\mathrm{SO}_{2}$ and ash (AI) from volcanic clouds. 
Eruption of Popocatepetl: May $17^{\text {th }} 2013$

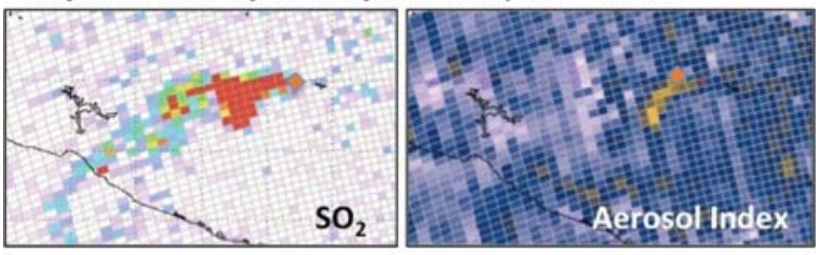

Eruption of Mt. Pavlof: May $19^{\text {th }} 2013$

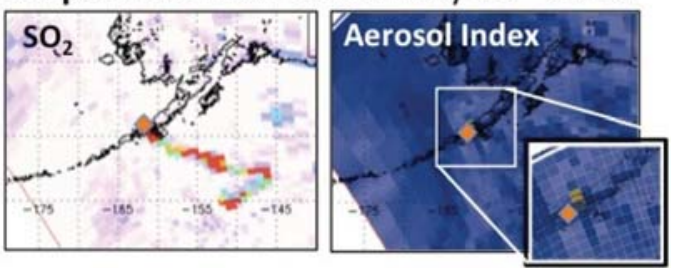

Figure 1. OMPS Volcanic Products. OMPS $\mathrm{SO}_{2}(\mathrm{DU})$ and UV Aerosol Index (AI, dimensionless, yellow color marks high positive AI values $>1$ that indicate presence of ash) for relatively small eruptions of Popocatepetl in Mexico and Mt. Pavlof in Alaska.

The OMPS instrument has been providing well-calibrated UV measurements for two years. Recently developed OMPS volcanic $\mathrm{SO}_{2}$ and AI data products have been implemented at NASA using a fast NRT OMI algorithm [Yang et. al, 2007]. The OMPS NRT volcanic products $\left(\mathrm{SO}_{2}\right.$ and Aerosol Index (AI)) are found to be of comparable or better quality than those from OMI. These volcanic products have begun a transition from NASA data production to our operational partners at NOAA NESDIS, Geographic Information Network of Alaska (GINA), Finnish Meteorological Institute (FMI) and US Geological Survey (USGS) to further improve their DSSs for early VA warning.

\section{Direct Readout}

At high latitudes polar orbiting satellites provide better coverage and spatial resolution than geostationary satellites; the refresh rate also increases because of the orbital overlaps. Near-realtime volcanic data products from the polar orbiting satellite OMI are delivered from NASA with about a 3 hour latency. Most of the latency time accumulates while waiting for the satellite to passby a data downlink station. Once the data is downloaded from the satellite, processing of the satellite data is on the order of several minutes. The latency time for polar orbiting satellite data can be drastically reduced by taking advantage of direct broadcast (DB) capability. DB capability allows external ground stations to directly receive satellite data as the satellite passes over that particular region. This method of receiving satellite data only gives users data around the region of the ground station but it allows the users to process and produce the volcanic data products within minutes of the measurement time. Direct Readout (DR) of $\mathrm{OMI} \mathrm{SO}_{2}$ and AI data over North Atlantic and Europe by FMI demonstrated the benefits of polar orbiting satellites to monitor high-latitude regions with a very low latency (Figure 2).
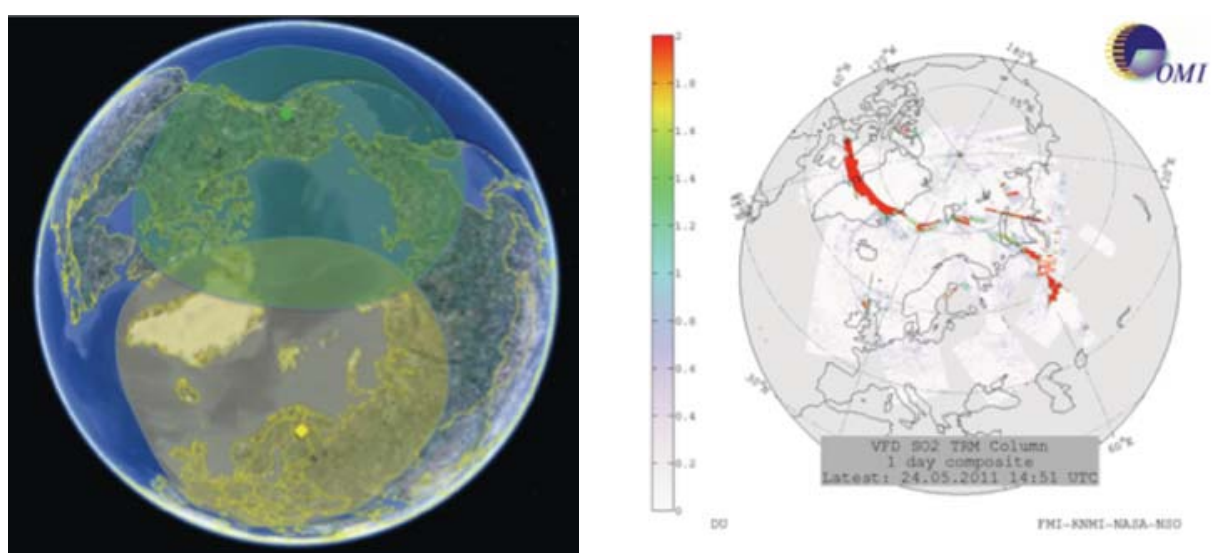

Figure 2. Direct Readout Coverage. Left: The image shows the geographical extent of the Aura (similar to OMPS) direct broadcast receiving with FMI satellite downlink station in Sodankylä in Northern Finland (yellow) and new proposed ground station in Alaska. Right: Several orbit composite OMI volcanic $\mathrm{SO}_{2}$ image from Grimsvotn eruption in Iceland on 24 May 10 April 2010. The volcanic $\mathrm{SO}_{2}$ and AI maps are processed and made available at the web site: http://omivfd.fmi.fi within $\sim 15$ minutes of the satellite acquisition. Typically several orbits from each polar orbiting satebite are processed every day [Hassinen et al

American Institute of Aeronautics and Astronautics 
NASA's Direct Readout Program has been instrumental in the development of DR capabilities for NASA satellite data. The NASA Direct Readout Laboratory (DRL) serves as the implementation arm of the NASA DR Program, which has co-sponsored the development of the International Polar-Orbiter Processing Package (IPOPP). IPOPP is a generalized data processing framework that presently hosts more than 34 Level-2 (L2) algorithms for 10 operational applications supporting 220 users. This service yields access to algorithms, software and information services for over 2000 registered users. The IPOPP has been useful in successfully bridging science algorithms to end-user applications for the Terra, Aqua and SNPP community. DRL and S-NPP Ozone Product Evaluation and Algorithm Test Element (OPEATE) have implemented a proof-of-concept prototype implementation of the OPEATE's OMPS Nadir Level-1/Level-2 algorithms thereby producing $\mathrm{SO}_{2}$, AI, Ozone, UV Aerosol Index (proxy for ash) maps in the direct readout environment at the DRL. Cooperation with FMI on implementing OMPS retrieval software has led to a successful test to process DR OMPS data and will be operational in the near future. Cooperation with the Geographic Information Network of Alaska (GINA) will expand the OMPS DR coverage from Finland to Alaska (Figure 2). This joint effort by GINA in Alaska and FMI in Finland will allow for near complete coverage of the north polar region; providing data with a latency time of that similar to geostationary satellite data.

Satellite data will be ingested into existing volcano monitoring systems at Washington and Anchorage VAACs and at the Alaska Volcano Observatory (AVO), a combined program of the U.S. Geological Survey, the University of Alaska Geophysical Institute, and the Alaska Division of Geological and Geophysical Surveys. AVO has been a pioneer in the use of satellite data to aid in monitoring volcanic activity and characterizing eruptions. They work closely with the National Weather Service (Anchorage VAAC and Central Weather Service Unit, CWSU), the Federal Aviation Administration (FAA), and Department of Defense to provide guidance on the location of potentially hazardous volcanic clouds from eruptions in Alaska, and those in the Russian Far East that enter Alaskan airspace. The AVO serves a critical function in the North Pacific as the link between newly developed scientific products for volcanic cloud analysis and their use in operational decision-making. The AVO has developed image analysis system aids in decision support collaboration between agencies (http://volcview.wr.usgs.gov). A capability to view NRT $\mathrm{SO}_{2}$ and VA images will improve the abilities of partner agencies (NWS, AAWU, and CWSU) to monitor and track potentially hazardous volcanic clouds. The DR data received at FMI will be used in the same way in the SACS service to support the London and Toulouse VAACs in their tasks for Europe, northern Atlantic and Arctic Sea.

\section{Integration of Satellite Data into Forecast Models}

Decisions about flight safety in the presence of volcanic ash are ultimately the responsibility of the individual airlines, who work in collaboration with weather agencies (e.g. NWS and NESDIS), air traffic regulators (e.g. FAA) and volcano observatories (e.g. USGS). Forecasting future volcanic ash cloud position is critical to their decision making process. Volcanic Ash Advisory Centers (VAACs) are the decision support systems (DSS's) which disseminate Volcanic Ash Advisory Statements to the aviation community. Along with volcano monitoring data, the assimilation of satellite data products into volcanic emissions models is crucial to ensure accurate forecasts of volcanic ash.

Forecasting the transport of volcanic clouds from explosive eruptions is difficult. Many properties crucial for forecasting volcanic clouds are frequently estimated from little information. Uncertainty in these parameters can lead to inaccurate short-term forecasts and highlights the need for an integration of satellite observations and forecasting models. By combining information from satellite observations and model simulations, crucial forecasting parameters can be better constrained to produce more accurate forecasts.

Simulating a volcanic cloud requires knowledge about the timing and duration of the eruption, the injection altitude of the volcanic emissions, and the amount that was emitted. If attempting to simulate volcanic ash, the size distribution of the ash particles must also be estimated. When attempting to produce operational forecasts of volcanic cloud transport, direct observations of these parameters are often not available. This is where the union of satellite observations with transport models can greatly advance capabilities in forecasting volcanic clouds.

Satellite observations are useful in their ability to derive accurate estimates of volcanic cloud tonnages and yield accurate maps of their horizontal distributions. However, estimating eruption source parameters (height and duration) require the use of transport models. These parameters can be qualitatively estimated using back trajectory methods constrained by satellite data [Krotkov et. al, 2010; Hughes et. al, 2012]. These methods were tested using OMPS volcanic data products to estimate eruption source parameters of the 2012 eruption of Copahue (Figure 3). Specifically, vertical stacks of back trajectories were initialized at the satellite measurement locations and driven

4

American Institute of Aeronautics and Astronautics 
backwards in time, towards the known location of the volcano. The subset of trajectories that track from the satellite observation back to within a minimum distance of the volcano describe the set of possible transport paths for the observed volcanic cloud. Probability Distribution Functions (PDFs) derived from this trajectory subset allows us to make estimates of the most probable injection time sequence and altitude of volcanic emissions [Hughes et. al, 2012]. Qualitative estimates of eruption source parameters can then be fed into the on-line Goddard Earth Observing System, Version 5 (GEOS-5) and the Goddard Chemistry Aerosol and Radiation Transport (GOCART) model to produce $\mathrm{SO}_{2}$ and volcanic ash forecasts. This process is demonstrated in Figure 3. The top panels (a,b,c) of Figure 3 show the initial observations (a) used to generate an estimate of the height/time profile of the eruption (b) which is then fed into GEOS-5/GOCART to produce a hindcast (c). The bottom panel is the same, but uses later observations of the $\mathrm{SO}_{2}$ cloud (d) and thereby producing a better estimate of the height/time profile (e) and subsequent hindcast (f). For a comparison, the VAAC reports for this eruption estimate the height/time profile as the dashed orange box noted in (b) and (e).

(a)

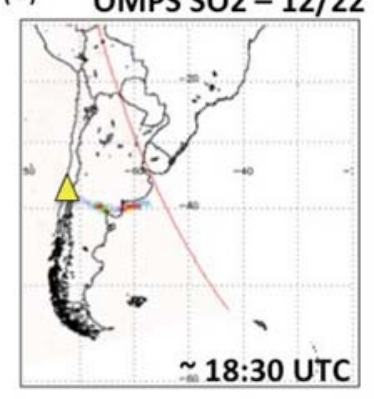

(d) OMPS SO2-12/23

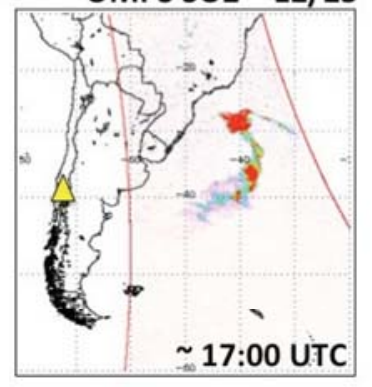

(b)

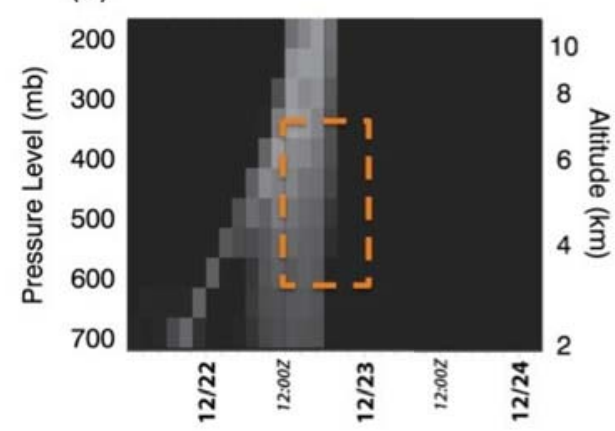

(c) GOCART SO2: 12/23

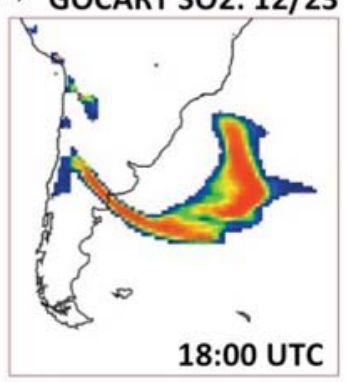

(f) GOCART SO2: $12 / 23$

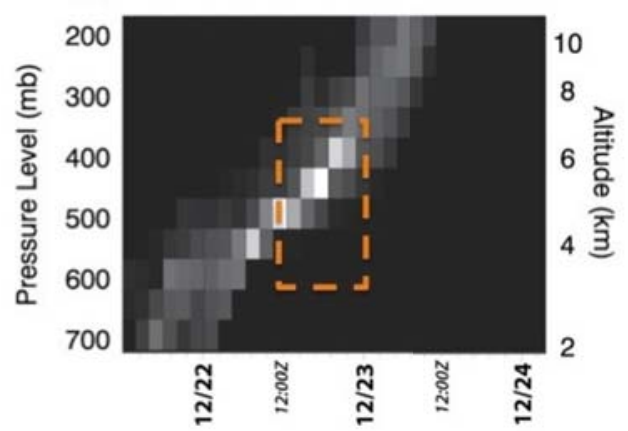

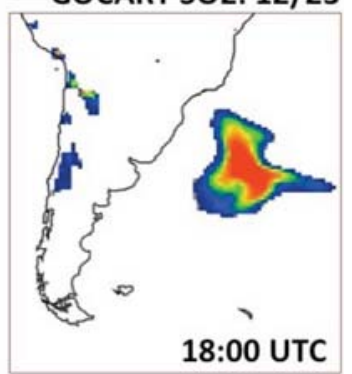

Figure 3. Estimation of Eruption Source Parameters. OMPS observations on December 2012 eruption of Copahue are show for $22^{\text {nd }}(a)$ and $23^{\text {rd }}(d)$. The temporal - height PDF of the Copahue eruption (b) and (e) are derived from back trajectories initialized at the OMPS observations in (a) and (d), respectivly. In (c) and (f), the GEOS-5/GOCART model was used to simulate the Copahue eruption using the temporal - height PDFs in (b) and (e), respectively, in order to reproduce the OMPS observations from December $23^{\text {rd }}(d)$. The source term estimates from the VAAC reports are noted as orange dashed boxes in (b) and (e) [Height: $3 \mathrm{~km}-7.6 \mathrm{~km}$; Duration: 12h; Start Time: 12/22/2012 12:00 UTC].

Eulerian models, like GEOS-5/GOCART, explicitly represent chemical/physical processes in volcanic clouds to provide $4 \mathrm{D} \mathrm{SO}_{2} /$ aerosol/ash mass concentrations $\left(\mathrm{mg} \mathrm{m}^{-3}\right)$, as opposed to most Lagrangian/trajectory models. The accuracy of the NASA Eulerian GEOS-5/GOCART model to forecast $\mathrm{SO}_{2}$ cloud drift and dispersal was evaluated, when driven with published eruption source parameters from Volcanic Emission Inventory data [Chin et. al, 2000]. While forecasting volcanic ash is the primary concern for the aviation community, $\mathrm{SO}_{2}$ is an important proxy for the presence of volcanic ash [Thomas and Prata, 2011]. The model hindcast of the 2008 eruption of Kasatochi was 
compared with $\mathrm{OMI} \mathrm{SO}$ observations and was found to be in a fairly consistent agreement over the period of 5 days after the eruption. The simulated temporal evolution of the total $\mathrm{SO}_{2}$ mass due to conversion to sulfate aerosols follows OMI observations with a fairly consistent $10 \%$ offset. Such offsets can be easily corrected with data assimilation techniques. The shape of the simulated cloud qualitatively matches OMI observations, but some discrepancies are also evident. These are likely due to the daily temporal resolution of the source eruption parameters. The model source term was recently updated to allow for much finer temporal estimates of the eruption source parameters, down to the order of minutes.

\section{Injesting Forecasts into DSS}

A volcanic ash module for GEOS-5/GOCART is currently being developed. The 4D aerosol/ash mass concentration forecasts it produces will provide VAACs, air traffic managers, and aircraft operators with timely and accurate information on volcanic ash hazards. Volcanic ash status and forecasts can then be translated into disruptive effects on planned aviation operations and potential mitigation strategies. Integration of volcanic ash forecasts into air traffic management tools by companies such as Metron Aviation will allow aviation stakeholders to reschedule operations in an efficient manner, thereby realizing full benefit of volcanic ash forecasts. This capbiliity was tested using a GEOS-5/GOCART hindcast of the $\mathrm{SO}_{2}$ emissions from the 2010 eruption of Iceland's Eyjafjallajokull (Figure 4).
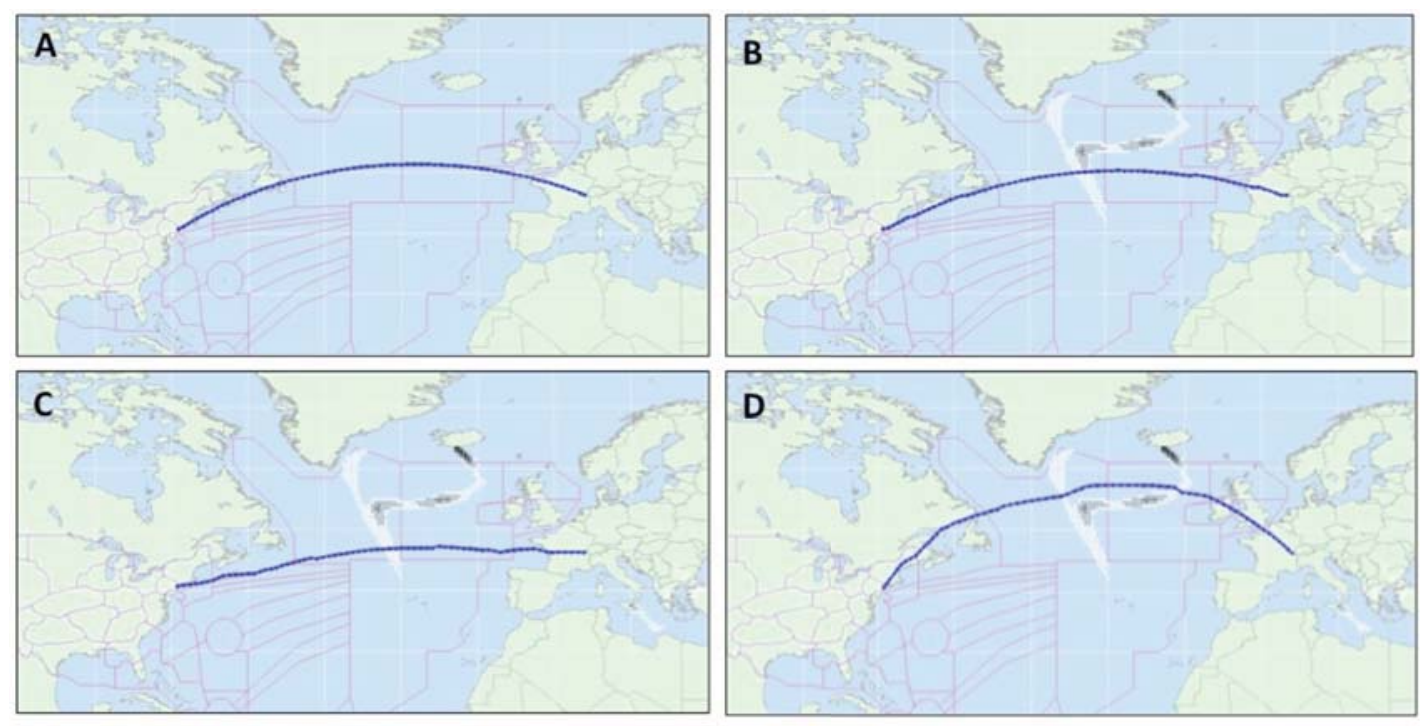

\begin{tabular}{|c|cccc|}
\hline SO2 Mass & \multicolumn{4}{|c|}{ Arc Cost Multiplier } \\
$\mathrm{mg} / \mathrm{m}^{\wedge} 2$ & A & B & C & D \\
\hline 20 & 1 & 1 & 1 & 1 \\
40 & 1 & 2 & 4 & 8 \\
60 & 1 & 3 & 9 & 27 \\
80 & 1 & 4 & 16 & 64 \\
100 & 1 & 5 & 25 & 125 \\
\hline
\end{tabular}

Figure 4. Optimized Flight Paths Around Volcanic Clouds. In (A) through (D), the optimized flight path from France to the U.S.A is shown. The optimized flight path is based on minimizing both the flight path and the cost associated with airplane-ash interactions. The presence of a volcanic cloud is included in $(B),(C)$, and (D), but not in (A). The "cost multiplier" associated with ash-airplane interactions is assumed to be linear in (B), quadratic in $(C)$, and cubic in (D). The table at the bottom summarizes the increased values of the "cost multiplie" with respect to airplane-ash interactions. 
Metron Aviation has developed route optimization techniques for computing the least cost path accounting for hazards such as volcanic ash. Figure A shows the nominal least cost path defined by the great circle arc. In Figure B, a small cost multiplier has been added to arcs passing through volcanic ash. The cost multiplier is directly proportional to the density of the ash. A quadratic cost multiplier is used in Figure $\mathrm{C}$ which results in a noticeable shift in the least cost path relative to the great circle arc. In Figure D, the cost multiplier is cubic with respect to ash density, resulting in a substantial deviation from the great circle path. This route optimization capability can be used to evaluate the impact of en route hazards on flight time, fuel burn, and distance based on various cost multipliers.

This study has onlined many areas of improvement for volcanic cloud moitoring and forecasting capabilities. Cooperation with many other agencies will help complete the goals sought out by this study and ultimately improve the safety and economic hazards that volcanic eruptions pose on aviation.

\section{Acknowledgments}

The authors acknowledge support from the NASA Applied Sciences Program.

\section{References}

Chin, M., R.B. Rood, S.-J. Lin, J.-F. Muller, and A. M. Thompson, Atmospheric sulfur cycle simu-lated in the global model GOCART: Model description and global properties, J. Ge-ophys. Res., 105, D20, 4671-24687, 2000.

ESA 2010, Monitoring volcanic ash from space, C. Zehner (editor). Proceedings from ESA-EUMETSAT workshop on the 14 April to 23 May 2010 eruption at the Eyjafjoll volcano, South Iceland, STM-280, ESA/ESRIN, July 2010

Guffanti, M., T. J. Casadevall and K. Budding (2010), Encounters of aircraft with volcanic ash clouds: a compilation of known incidents, 1953-2009. U.S. Geological Survey Data Series 545, ver. 1.0, 12 p., plus 4 appendixes including the compilation database.

Hassinen, S., J. Tamminen, A. Tanskanen, G. Leppelmeier, A. Malkki, T. Koskela, J. M. Karhu, K. Lakkala, J. P. Veefkind, N. A. Krotkov, and O. Aulamo (2008), Description and validation of the OMI very fast delivery products, J. Geophys. Res., 113, D16S35, doi:10.1029/2007JD008784.

Hughes, E. J., L. C. Sparling, S. A. Carn, and A. J. Krueger (2012), Using horizontal transport char-acteristics to infer an emission height time series of volcanic SO2, J. Geophys. Res., 117, D18307, doi:10.1029/2012JD017957.

Krotkov, N. A., M. R. Schoeberl, G. A. Morris, S. Carn, and K. Yang (2010), Dispersion and life-time of the SO2 cloud from the August 2008 Kasatochi eruption, J. Geophys. Res., 115, D00L20, doi:10.1029/2010JD013984.

Thomas, H. E. and Prata, A. J.: Sulphur dioxide as a volcanic ash proxy during the April-May 2010 eruption of Eyjafjallajökull Volcano, Iceland, Atmos. Chem. Phys., 11, 6871-6880, doi:10.5194/acp-11-6871-2011, 2011.

Yang, K., N. A. Krotkov, A. J. Krueger, S. A. Carn, P. K. Bhartia, and P. F. Levelt (2007), Retrieval of large volcanic SO2 columns from the Aura Ozone Monitoring Instrument: Comparison and limitations, J. Geophys. Res., 112, D24S43, doi:10.1029/2007JD008825. 